\title{
Alinhamento estratégico: o papel da informação na integração de propósito, processos e pessoas em Instituições no Brasil
}

\author{
Antonio Rodrigues de Andrade \& Aldo de Albuquerque Barreto \\ UNIRIO / UNAMA \\ E-mail: Prof.arandrade@gmail.com/Aldo.barreto@gmail.com
}

\begin{abstract}
Resumo
Não há gestão possível sem informação e ao lado de funções tradicionais, a empresa deve incorporar a função informacional. Como uma função de caráter transversal, não se limita somente ao ambiente interno da organização. Percorre órgão a órgão de uma forma transversal, para ligando-os entre si e ao ambiente externo. Para que o gerenciamento da informação seja eficaz, eficiente e efetivo no cumprimento de seu objetivo deve se saber com clareza o que é a informação para a empresa, quem a possui, como é conservada, quem é o responsável pelo gerenciamento, como controlar e utilizar a informação. Assim, esta pesquisa tem por objetivo avaliar a informação e seus fluxos como elementos integradores do propósito, do processo e das pessoas em organizações receptoras, processadoras e disseminadoras de infor-

mação no município do Rio de Janeiro. Ela insere-se no contexto gestão da informação no aspecto em que a informação e seus fluxos colaboram com os vários componentes do processo de alinhamento estratégico da organização. A metodologia utilizada teve um caráter qualitativo e de pesquisa exploratória e descritiva. Valeu-se de pesquisa de campo na forma de entrevistas estruturadas com profissionais da gestão das organizações pesquisadas. Através das entrevistas, buscouse conhecer as organizações pesquisadas em relação à integração entre propósito, processos e pessoas. A análise dos dados foi interpretativa. Constatou-se que as organizações pesquisadas, de maneira geral, não utilizam a informação em sua gestão com a mesma qualidade que captam e disseminam as informações objeto de seus objetivos organizacionais.
\end{abstract}

Palavras-chave: alinhamento estratégico; propósito; processo; pessoas; informação. 


\begin{abstract}
There could not be management without information and alongside the traditional functions of an organization and its incorporated informational function. Considering the function of lying across and not only limited to the organization's internal environment. For information management to be efficient and effective in meeting its goal they must be to know clearly what is the information concept for the company, who has it is , how it is conserved and who is responsible for managing, controlling and using it. Thus, this research aims to evaluate the information, and its integrating elements flows with the purpose to examine the process and people in the recipient organizations, also to observe its processors and disseminators in the municipa-

part of the information management aspect in the context of information flows and their work with the various components of the strategic alignment in the organization process. The methodology was qualitative, exploratory and descriptive.In the field, research was structured as interviews with professionals in the management of each organization surveyed. Through the interviews was intended to know the surveyed organizations regarding its integration between purpose, process and workers. Data analysis had an interpretive. The survey found that organizations in general do not use the information in its management with the same quality as they gather captured, and disseminated information used for its objectives and organizational goals.
\end{abstract} lity of Rio de Janeiro. This research is

Key-words: strategic alignment; purpose; process; people; information.

\title{
Introdução
}

\begin{abstract}
A vantagem competitiva das Organizações está passando a depender, cada vez mais, de sua capacidade de tomada de decisões, de gerar estratégias e transformar as estratégias em ações diárias, em que seus profissionais possam contribuir, gerando resultados significativos ao encontro de seus objetivos. Vemos a informação como objeto principal para que isso possa se concretizar.

A administração é a interpretação dos objetivos propostos pela empresa por meio do planejamento, organização, direção e controle de todos os esforços realizados em todas as áreas e em todos os níveis da organização, a fim de alcançar tais objetivos de maneira mais adequada à situação (Chiavenato, 1993).
\end{abstract}


Alinhamento estratégico: o papel da informação na integração de propósito, processos e pessoas em Instituições no Brasil

Cada empresa incorpora um modelo de gestão que, ao longo do tempo, vai sendo alterado e ajustando-se de forma a melhor contribuir com os seus objetivos. O modelo de gestão não é único nem rígido e varia de organização empresarial para organização empresarial, em função do desenvolvimento de variáveis internas e externas (Rodriguez \& Rodriguez, 2001).

A necessidade de as organizações promoverem o alinhamento de suas estratégias com os processos internos e os externos tem-se configurado como uma necessidade crescente. Além disso, a informação deve ser integrada aos produtos, serviços e, principalmente, às decisões. Essa integração torna-se função vital da gestão de qualquer empresa. Não há gestão possível sem informação.

A empresa possui uma dinâmica interação com seu meio ambiente, sejam clientes, fornecedores, concorrentes, entidades sindicais, órgãos governamentais e outros agentes externos. Além disso, possui uma estrutura de funcionamento composta por diversas unidades relacionadas entre si, que atuam de forma harmônica e estão orientadas para objetivos definidos, não só para a organização como para seus participantes (Porter, 1998).

A relevância que a informação assume, nesse contexto, dá-se na sustentação e no crescimento existente entre o sistema organizacional, o meio ambiente e seu funcionamento operacional. Um processo pelo qual a organização se informa sobre ela própria e sobre o seu ambiente, bem como informa o ambiente sobre ela própria. Isso implica em criação, comunicação, tratamento e memorização da informação. Além disso, o processo deve produzir resultados que permitam avaliar a qualidade da informação. Resultados quanto à quantidade, ao custo, ao tempo de geração e à sua utilidade para o usuário. A informação é um instrumento de integração fundamental, que necessita ser avaliada quanto ao impacto produzido nesse processo de integração organizacional.

As mudanças de mercado provocadas pelas alterações nas necessidades dos clientes fazem com que, a cada instante, as organizações tenham que se ajustar à nova realidade. Está no alinhamento estratégico o meio que a empresa possui para dar consistência entre planos, processos, ações e decisões que apoiem as estratégias, objetivos e metas globais da organização. A fim de torná-lo eficaz, faz-se necessário o entendimento das estratégias e metas, e a utilização de indicadores e informações complementares para possibilitar o planejamento, monitoramento, análise e melhoria nos setores de trabalho, 
nos principais processos e na organização como um todo. Nesse ponto, a informação desempenha um papel significativo (FPNQ, 2003).

Sendo assim, para o desenvolvimento e consecução de suas atribuições relacionadas ao planejamento, gerenciamento e execução, é necessário que o administrador das empresas tenha informações adequadas, específicas e pertinentes. A informação deve ser vista como o insumo básico para a realização das atividades do gestor, de forma que venha a contribuir para a tomada de decisão e efetiva melhoria no desempenho organizacional.

A Gestão Estratégica deve ser considerada como a criação, escolha e formulação da estratégia, a tradução em ação por meio da consecução das necessárias mudanças e, por fim, a monitoração e a avaliação da sua efetividade. A informação desempenha papel essencial na integração das três etapas, onde: (a) a informação na definição estratégica cria as condições para uma resposta competitiva mais eficaz da organização às exigências do ambiente; (b) a informação para a execução estratégica está relacionada à disseminação das definições estratégicas por toda a organização e contribuição à criação das condições para a sua implementação; e (c) o feedback da informação sobre o desempenho permite que reconheçam- se as necessidades de modificações e ajustes nas definições quando tornarem-se ineficazes (McGee e Prusak, 1994).

As informações, obtidas pelo monitoramento ambiental, subsidiarão a formulação estratégica da empresa, a definição de atuação dos processos e, consequentemente, das pessoas envolvidas. Embora, os estudos não abordem nenhuma empresa ou segmento econômico específico, ressaltam a sua importância para o processo de inteligência competitiva e organizacional desenvolvido ou por quem pretende desenvolvê-lo nas organizações.

A interação empresa - cliente, somente, será eficaz se o recebido e transmitido por ela for, efetivamente, percebido e aceito como tal pelos envolvidos no processo informacional. Isso vai ao encontro do apresentado por Barreto (1995) ao introduzir o conceito de assimilação da informação como um processo de interação entre os indivíduos e uma determinada estrutura de informação, possibilitando gerar uma modificação em seu estado cognitivo. Dessa forma, produz-se conhecimento que se relaciona, corretamente, com a informação recebida.

Barreto (1994) cunhou o termo estrutura significante quando, ao adaptar os conceitos de informação de Wersig, Nelling, Belkin e Robertson, apresentou o seu próprio conceito em que apresenta a informação como "estruturas 
Alinhamento estratégico: o papel da informação na integração de propósito, processos e pessoas em Instituições no Brasil

significantes com a competência de gerar conhecimento no indivíduo, em seu grupo, ou na sociedade.

Sempre presente em todos os períodos históricos, a informação tornou-se, ao final do século passado, um relevante fator de produção. Em um mercado cada vez mais globalizado e competitivo, a utilização da informação assume importante papel na orientação das estratégias das organizações. Vive-se uma fase cujas transformações aceleram-se nas tecnologias de informação, na comunicação e na configuração da economia.

O conhecimento da origem, da organização e da disseminação da informação deve ser encarado como condição fundamental para o crescimento das possibilidades de realizações estratégicas nas organizações. Por meio de um processo informacional alinhado aos objetivos organizacionais é que será possível, aos seus gestores, a interpretação, a transformação e a utilização da informação na tomada de decisão e nas escolhas estratégicas.

Assim, entende-se que a informação e, principalmente, a sua organização e o seu compartilhamento permitirão aos envolvidos, nas várias organizações públicas ou privadas, direta ou indiretamente, a prática do planejamento, monitoramento e controle de forma consistente.

Resumidamente, tudo isso nos leva a constatar a inexistência de um processo informacional sistematizado entre os vários atores responsáveis nas organizações, em que, fundamentalmente, o compartilhamento de informações e a utilização ótima da informação não são desenvolvidos.

Assim, esta pesquisa, tem por objetivo avaliar e apresentar o papel da informação como elemento integrador do propósito, do processo e das pessoas em organizações de captação, processamento e disseminação de informação por meio de um estudo de caso múltiplo. Ela insere-se no contexto gestão da informação no aspecto em que a informação e seus fluxos colaboram com os vários componentes do processo de alinhamento estratégico da organização. Com uma visão multidisciplinar analisa três Instituições Brasileiras quanto ao papel da informação no alinhamento estratégico.

\section{Método de estudo}

A metodologia utilizada teve um caráter qualitativo e de pesquisa exploratória e descritiva. Valeu-se de pesquisa de campo aplicada, na forma de entrevistas estruturadas, com profissionais da gestão das organizações pesquisadas 
e pesquisa bibliográfica e documental. Por meio da entrevista e documentos coletados, buscou-se conhecer as organizações pesquisadas quanto à integração entre propósito, processos e pessoas nas instituições que administram a captação, processamento e disseminação das informações. Foram selecionadas três instituições para a pesquisa todas em nível nacional: um Museu, uma Biblioteca e um Arquivo

A pesquisa de campo baseou-se nos procedimentos propostos por Alberti (1990). O primeiro procedimento é a identificação dos profissionais das empresas pesquisadas e em seguida, é feita uma sondagem para a realização da pesquisa e a formalização dos convites de participação. Foram consultados entre dois a cinco profissionais de cada Instituição pesquisada.

O roteiro de entrevista foi dividido em três partes considerando questões relacionadas com o propósito, os processos e as pessoas nas Instituições. Foram elaboradas dez questões para propósito relacionadas com planejamento estratégico, interação com os clientes/usuários e nível de inovação, quinze de processos abordando temas como modelo de gestão, uso de tecnologia da informação, conectividade, acesso e disponibilidade da informação e controle, por fim mais dez questões do tópico pessoas buscando identificar a captação, avaliação e capacitação de talentos.

As entrevistas com os gestores foram gravadas e transcritas. Foram, ainda, conferidas a fim de ser mantida a integridade da transcrição. No primeiro momento, a transcrição foi feita com o objetivo de concentração da fala do entrevistado nas respostas às perguntas elaboradas. No segundo momento, elaborou-se um ajuste nas respostas, considerando-se que, em certos momentos, algumas delas sobrepuseram-se a outras perguntas, ou foram respostas dadas em complemento a anteriores.

Concluídos esses procedimentos, o estudo apresenta interpretações objetivando avaliar e comentar um conjunto de informações para revisão, reflexão e interpretação do objeto do estudo, ou seja, a informação na integração de propósito, processos e pessoas. A análise dos dados foi interpretativa, tomando-se, por base, as informações relatadas pelos entrevistados considerando o corpo de conhecimentos pertinentes ao assunto nos campos das ciências de administração e da informação. 
Alinhamento estratégico: o papel da informação na integração de propósito, processos e pessoas em Instituições no Brasil

\section{Resultado da pesquisa}

O alinhamento estratégico é a essência da Gestão Estratégica, pois, é por meio dele, que haverá consistência entre planos, processos, ações e decisões para apoiar as estratégias, objetivos e metas globais da organização. Para que isso se realize, três elementos são considerados fundamentais: o propósito, os processos e as pessoas.

O primeiro componente para a definição da existência do alinhamento estratégico é o propósito. Nele, serão encontrados os elementos que permitirão avaliar a existência de uma formulação estratégica, bem como os mecanismos que permitirão à Organização proceder à integração por meio do desdobramento estratégico.

A classificação que esclarece as formas com que os gestores pensam sobre a realização de suas intenções e ações estratégicas são denominadas de racional, evolucionária e processual (Heijden, 2004)

A primeira delas, a abordagem racional, trata o pensamento e a ação separadamente. Esta abordagem é a que mais se aproxima de duas Instituições pesquisadas. O Arquivo e a Biblioteca apresentam elementos que permitem definir, como racional, a modelo de formulação e implementação estratégica das Instituições.

O Museu apresenta elementos mais próximos da abordagem processual: mais aberta ao ambiente e procurando ajustar-se conforme o que nele é percebido.

A abordagem processual, diferentemente das outras e, em especial, do racional, entende que é possível definir estratégias ótimas como o proposto pelo paradigma racional. Entretanto, para que isso se torne possível, as organizações devem tornar-se mais flexíveis, adaptáveis e capazes de aprender com seus próprios erros. O que é demonstrado pelo Museu, principalmente, quando se refere ao aprendizado que busca nas ações relacionadas com os seus clientes.

Duas Instituições, Museu e Arquivo Nacional, promovem a integração estratégica levando em consideração dois aspectos. O primeiro refere-se à informação definida no plano estratégico e desdobrada em objetivos e metas correspondentes e alinhadas com o plano inicial. O segundo refere-se às pessoas que participam do processo de planejamento. 
Cabe destacar que houve divergência de informações nas entrevistas realizadas na Biblioteca. Enquanto uma entrevistada informou sobre o planejamento estratégico da Instituição, a outra participante afirmava não reconhecer a existência de planejamento estratégico. Esta situação fragiliza a afirmação de que há desdobramento estratégico, pois ele se consolida com o conhecimento de todos na Organização a seu respeito.

Pode-se observar, no Museu, que a integração organizacional é fundamental ao alinhamento estratégico. Ela se dá através de reuniões constantes em todos os níveis, procurando garantir que todos tomem ciência e participem do movimento estratégico. As informações e as pessoas, em toda a Instituição, mobilizam-se para o cumprimento das operações e projetos vinculados com o plano estratégico de forma orquestrada.

No Arquivo, também, existe a preocupação de utilização da informação e da participação das pessoas. A busca da integração organizacional é uma preocupação da direção, que reúne a administração intermediária no processo de formulação estratégica, mas é garantida sua aplicação sistemática. A participação dos demais colaboradores da Instituição depende do comportamento das chefias em informá-los e recolherem suas informações para apresentação em fóruns superiores.

A comunicação por meio de Tecnologia da Informação não é explorada para a construção do alinhamento pelas três Instituições, que mais a utilizam para a operacionalização das ações e operações.

A busca de informações externas, principalmente, a do cliente, não é feita de forma proativa e, tampouco, a captura das informações recebidas é realizada de forma sistematizada pelas três Instituições. As informações são recebidas por canais instituídos como Fale Conosco, e-mails e caixa de sugestões no dia a dia. As três Instituições conhecem bem seus clientes, mas não os exploram no sentido de contribuírem com suas informações no processo estratégico. Mas, não pode ser ignorado que, ao ouvi-los, mesmo de forma reativa e com os meios que possuem, aproveitam as informações fornecidas para melhorias operacionais.

Todas se dizem inovadoras, mas isso ocorre com limitações, pois são organismos públicos, onde inovar não é uma prática constante e comum, embora demonstrem ações nesse sentido, principalmente, a Biblioteca e o Museu.

Quanto ao controle existente nas Instituições, ele é desenvolvido levandose em consideração indicadores estabelecidos para tal fim mas, na maioria, de 
Alinhamento estratégico: o papel da informação na integração de propósito, processos e pessoas em Instituições no Brasil

forma que satisfaçam as informações que devem estar contidas nos Relatórios de Gestão.

O planejamento existe nas Instituições por força dos planos plurianuais que devem ser desenvolvidos e dos orçamentos, que devem ser apresentados por imposições legais aos órgãos públicos federais. Contudo, a grande questão é se possuem um caráter estratégico.

O segundo componente para a definição da existência do alinhamento estratégico é o processo. Aqui, entendido como a forma de implementação da estratégia na Organização, bem como o controle de sua execução. Duas abordagens podem ser constituídas para a implementação estratégica. Uma delas é a adoção da orientação por processos e outra a abordagem por orientação funcional.

Pode-se constatar que as três Instituições adotam a abordagem orientada por função. Possuem uma estrutura organizacional hierarquizada e centralização no processo decisório, que confirma o modelo de gestão mecanicista.

Tanto o Instituição 2 - Arquivo quanto a Instituição 3 - Biblioteca possuem iniciativas de adoção da abordagem por processos. Inclusive, têm alguns processos mapeados mas, embrionários, não demonstram relevância para a sua análise.

Os aspectos relacionados com o item Processos referentes à implementação estratégica são: o desenho dos processos e definição de atividades/tarefas para a realização estratégica, o uso da Tecnologia da Informação aplicada na Organização e os fluxos de informação. Outros aspectos a serem considerados relacionam-se com o acompanhamento e o controle estratégico. São eles: a existência de indicadores de desempenho quanto à sua constituição e à sua utilização, bem como as formas de realização do acompanhamento e controle estratégico.

Tanto implementação e controle são elementos que, após a formulação estratégica, precisam ser definidos para que a organização conduza as ações necessárias ao alcance de seus objetivos e metas e, assim, adotar um modelo de gestão e fundamental.

A abordagem funcional, adotada pelas três Instituições, possui uma dinâmica informacional que ocorre entre os vários ambientes organizacionais. Os ambientes organizacionais estão nos níveis hierárquicos da Organização, ou seja, nível estratégico, nível tático e nível operacional. 
Nesse modelo, é comum a descida de fluxos pelos níveis hierárquicos, do estratégico ao operacional, onde a informação deve se propagar a fim de desenvolver a execução estratégica e construir a integração organizacional. E, ainda, subir fluxo de informações do nível operacional ao estratégico para acompanhamento e controle das operações e projetos organizacionais.

Observa-se, pela pesquisa desenvolvida, que a dinâmica informacional corresponde aos fluxos descritos, onde informações apresentadas nos planos, programas e projetos são desdobrados pela cadeia hierárquica e, através dela, sobem informações de controle por meio dos indicadores de desempenho apurados.

A pesquisa não se preocupou com a abrangência e aprofundamento das informações contidas nos planos desdobrados, bem como dos indicadores de desenvolvidos, ou seja, não foi objeto da pesquisa avaliar conteúdo e, sim, o movimento (processo) da realização estratégica. Nesse sentido, as Instituições pesquisadas, teoricamente, cumprem o estabelecido para a implementação estratégica.

O terceiro e último componente para a definição da existência do alinhamento estratégico está relacionado às pessoas. É nele em que serão encontrados os elementos que permitirão avaliar a existência de uma capacitação apropriada para a construção do alinhamento.

Apesar de as Instituições, cada uma à sua maneira, estimular a participação dos colaboradores no planejamento estratégico, no quesito capacitação orientada para a estratégia, todas apresentaram a mesma situação de inexistência de um plano de capacitação que busque atender o alinhamento estratégico especificamente

\section{Considerações finais}

Este trabalho procurou avaliar a informação aplicada ao alinhamento estratégico das Organizações com ênfase na relação entre o propósito, os processos e as pessoas em organizações de captação, processamento e disseminação de informação. Foram selecionadas uma Biblioteca, um Museu e um Arquivo para a pesquisa.

Ao longo do trabalho, procurou-se relacionar a dinâmica das três Instituições com o alinhamento estratégico para efeito da integração organizacional, tendo-se em vista a consecução de seus objetivos estratégicos. 
Alinhamento estratégico: o papel da informação na integração de propósito, processos e pessoas em Instituições no Brasil

As três Instituições pesquisadas apresentam uma forte influência no seu modelo de gestão tradicional por serem organismos públicos e estarem condicionadas às regulamentações inerentes a essa situação. Contudo, pôde-se observar, nas entrevistas realizadas, que existem ações institucionais que as aproximam de modelos mais contemporâneos de gestão.

Todas as três Instituições apresentam uma estrutura organizacional rígida, permanente e flexível imposta pelas regulamentações devidas, contudo, em duas delas, Museu e Biblioteca, desenvolveram-se mecanismos informais para a busca de maior eficiência e eficácia em suas ações, sem com isso ferir qualquer ditame legal.

Há uma preocupação das três Instituições que o sistema de comunicação seja tanto vertical quanto horizontal. Isso ficou claro nas entrevistas realizadas no Museu e no Arquivo, não tendo sido detectado com maior precisão na Biblioteca. Confiabilidade colocada sobre as regras e regulamentos formalizados por escrito.

Controles são exercidos por indicadores de desempenho constituídos para atividades consideradas importantes nas três Instituições. Mas, os resultados de medição não são comunicados, não são analisados criticamente. E, também, não são usados, sistematicamente, para as atividades de melhoria, de forma que toda a Instituição tome conhecimento e possa atuar na melhoria do desempenho organizacional.

A Instituição que parece estar mais sintonizada com o seu ambiente é o Museu. Em seguida, a Biblioteca e, depois, o Arquivo. Contudo, as três Instituições não possuem um sistema formal de coletar dados de satisfação e insatisfação do seu "cliente". Portanto, não têm condições de utilizar essas informações para melhoria.

Por fim, constatou-se que todas as Instituições utilizam a informação a seu jeito não ficando demonstrado um padrão quanto a sua utilização para o alinhamento estratégico entre elas. Embora existam esforços no sentido de buscar um alinhamento para a consecução estratégica não está na informação o componente principal para proporcionar a integração organizacional.

\section{Referências Bibliográficas}

Alberti, V. (1990). História oral: a experiência do Cpdoc. Rio de Janeiro: FGV. 
Barreto, A.A. (1994). A questão da informação. São Paulo Em Perspectiva, São Paulo, n. 4, v. 8, out./dez.

Barreto, A.A. (1995). Valor agregado: Aspectos conceituais. Seminário Internacional Valor Agregado à Informação. Rio de Janeiro: SENAI/CNI/ CIET.

Chiavenato, I. (1993). Introdução à Teoria Geral de Administração. São Paulo: Makrobooks.

Chiavenato, I. (2000). Administração: teoria, processo e prática. São Paulo: Makron Books.

FPNQ - Fundação Prêmio Nacional para a Qualidade. (2003). Primeiros passos para a excelência. Brasília: FPNQ.

Heijden, K.V.D. (2004). Planejamento de Cenários: a arte da conversação estratégica. Porto Alegre: Bookman.

Kaplan, R.S. \& Norton, D.P. (1997). A estratégia em ação: balanced scorecard. Rio de Janeiro: Campus.

McGee, J. \& Prusak, L. (1994). Gerenciamento estratégico da informação. Rio de Janeiro: Editora Campus.

Porter, M.E. (1998). A vantagem competitiva das nações. In C.A. Montgomery \& M.E. Porter, (Org) Estratégia: a busca da vantagem competitiva . Rio de Janeiro: Campus.

Rodriguez y Rodriguez, M.V. (2001). Gestão do Conhecimento: reinventando a empresa para uma sociedade baseada em valores intangíveis. Rio de Janeiro: IBPI Press. 